\title{
EFFECTS OF VARIOUS SOIL ENVIRONMENTAL STRESSES ON THE OCCURRENCE, DISTRIBUTION AND EFFECTIVENESS OF VA MYCORRHIZAE
}

\author{
A.G. KHAN \\ Department of Biological Sciences, Faculty of Business and Technology, \\ University of Western Sydney Macarthur, P.O. Box 555, \\ Campbelltown N.S. W. 2560, Australia
}

\section{INTRODUCTION}

The vesicular - arbuscular (VA) mycorrhizal fungi are geographically ubiquitous soil inhabitants and form universal symbiotic relationship with plants from every phylum. These fungi link host plants with host soils and their biota in the mycorrhizosphere and play an important role in plant health, productivity and soil structure. Although VA mycorrhizal fungi do not show any host specificity, there is increasing evidence that various climatic and edaphic environmental factors such as land use and management practices, physical, chemical and biological properties of host soils and host plant characteristics influence their occurrence, taxonomic distribution and effectiveness. The interaction of these factors with vesicular-arbuscular mycorrhizae (VAM) is poorly understood except in a few cases. It is now very clear that VA mycorrhizal associations are ecologically significant factors that require more attention than previously accorded.

This paper discusses the occurrence, distribution and significance of VAM in environmentally stressed soil conditions that limit plant growth such as drought, waterlogging and salinity.

Key words: Mycorrhizas/Environmental factors/Waterlogging/Soil salinity/Growth development stages/ Inoculum.

\section{VAM AND DROUGHT}

Evidence is accumulating which supports the contention that VA mycorrhizal fungi are present in arid regions in xerophytes (Khan 1974) and improved resistance of plants to water stress in controlled environments (Bethlanfalavay et al. 1988), as well as in the field (Sylvia et al. 1993), primarily due to improved nutritional status of plants.

VAM are known to occur in plants growing naturally in pioneer arid habitats of sand dunes, industrial waste lands and disturbed sites such as coal tips and 
strip-mined land (Khan 1978). Evidence has also been accumulating, linking the presence of VAM infection to survival and improved plant growth in mine soil (Khan 1981). VAM has great potentials in the reclamation of drastically disturbed land and arid lands for agriculture. Our findings, that different VAM endophytes had quantitatively different effects on growth of onions in unsterilized coal waste (Khan 1981) and the extent of colonization of onion roots was dependant upon inoculum density (Khan 1988), may have practical implications for the establishment of a particular endophyte in arid conditions and the extent of plant response to the infection. VAM symbionts can assist in the accelerated rehabilitation of unsightly industrial waste lands. Increased growth of grasses and other indigenous flora on the dump sites may be obtained by either increasing the population of ecologically adapted VA endophyte strain(s) and or transplanting plants pre-inoculated with suitable strain(s) instead of applying and fertilising top soil cover. Commercial quantities of VAM inoculum are now available for revegetation efforts of mined or cleared land. Nurseries selling plants for revegetation or transplants into fumigated soils are the immediate beneficiaries of the VAM biotechnology. Also, the determination of abiotic factors governing efficiency of an isolate must be made before we can realistically select superior VAM fungal isolates for use in the colonization of disturbed sites.

\section{VAM AND WATERLOGGING}

VAM occur over a wide range of soil water contents (Khan 1974). VAM colonization has been found in plants growing in frequently waterlogged soils (Khan 1993a), as well as in free floating and submerged aquatic plants (Khan \& Belik 1994). The VAM fungi are aerobic, so soil water and aeration influence their distributions and effectiveness in soils and VAM spore numbers along with VAM infection are positively correlated to redox potential values (Khan 1993b). A relationship between characteristics of VAM infection and soil moisture gradient was found in a study of a Casuarina cunninghamiana-transect on a creek embankment (Khan 1993a). Typical vesicles and arbuscules were found in roots from drier soil. Roots from relatively wet soils lacked arbuscules but contained large liquid filled intracellular vesicles. Typical vesicles and arbuscules were absent in flooded creek beds where roots were associated with coenocytic intracellular hyphae with abundant lipid contents. VAM roots of submerged aquatic plants also harboured vesicles and/or coenocytic hyphae only, however, arbuscules were rare or absent. It is possible that the endobiont may be existing even in the aquatic plants recorded as non-mycorrhizal in the form of mycelia, not considered by the researchers as VAM infection. VAM fungi become non-functional in these habitats when the soil is saturated for extended 
periods of time (Liberia et al. 1983). However, when sites become seasonally dry, a functional symbiosis redevelops (Khan 1993c). The variations between functional and non-functional associations may be common in wet and waterlogged habitats where conditions fluctuate on a seasonal or annual basis to favour or hinder mycorrhizal formation. The nature of the periodic non-functional associations, whether benign or a mild form of parasitism, is unknown and requires further study, as suggested by Anderson et al. (1994). These fluctuations may be due to a change in redox potential from reducing to oxidising by the lateral liberation of oxygen from plant roots (Kludge et al. 1993). The reports of the presence of VAM under waterlogged conditions may be related to the (1) internal oxygen transport from the stem to the root due to presence of aerenchyma, (2) the oxygen release from the roots of large trees to support VAM fungi, (3) strains of VAM fungi in the sediments that can withstand highly reduced habitats, or (4) a combination of all these factors. But these have not been demonstrated and further studies are needed.

The ability of VAM to tolerate submersion became evident from various studies on the commercial production of inoculum by using aerated nutrient solutions in hydroponics or aeroponics. Many global studies have established that VAM fungi can infect permanently submerged plants under natural condition (Khan and Belik 1994). However, the process of infection and various biotic and abiotic factors in the aquatic environment affecting the process are unknown and further research is needed to understand the ecological significance of VAM in these habitats. An understanding of the adaptions and mechanisms of plants living in or on water is valuable in explaining the interaction between plants, VAM fungi and sediment/water including its biota as a dynamic system. Mycorrhizal infection of roots causes significant physiological changes in the host plant which make the mycorrhizal plant grow and respond to environmental stresses differently from a non-mycorrhizal plant.

Although the occurrence of mycorrhizal infection in waterlogged and submerged aquatic plants has been known for some time, very few workers have attempted to identify species involved in these associations (Khan and Belik 1991). Various global studies suggest that environmental factors such as soil moisture, soil type and soil gases influence the taxonomic distribution of VAM fungi. Spores of Gigaspora margaritawere reported from the mycorrhizospheres of various wet and submerged plants (Khan and Belik 1994), which suggests that this species may be adapted to grow in these conditions of low oxygen availability and high $\mathrm{P}, \mathrm{N}$, and phytotoxin contents of the reduced sediment. Although the presence of spores in aquatic sediments suggests that they probably enter the aquatic sediments through run-off from terrestrial ecosystems, information is accumulating that support the 
contention that there is significant genetic and physiological diversity in population of VAM fungi from dissimilar environments (Bethlenfalvay 1992). Further research is needed to demonstrate this 'ecological specificity'. Studies are also needed to separate the effects of flooding stress on the VAM fungus from those on the host root.

\section{VAM AND SOIL SALINITY}

VA-mycorrhizal fungi occur naturally in saline environment (Khan 1974; Khan and Belik 1994) and several researchers who investigated the relationship between soil salinity and occurrence of mycorrhizae on halophytes have indicated that the number of VAM spores or infectivity of VAM fungi based on germination and subsequent hyphal growth decreased with increasing salt (Juniper and Abbott 1993). Saline soils pose physiological stresses such as $\mathrm{NaCl}$ toxicity and low osmotic potentials to plants growing in them. These stresses effect the growth of plants fungus or both. $\mathrm{NaCl}(750$ $\mathrm{mg} \mathrm{NaCl}$ per $\mathrm{kg}$ soil) reduced the number of vesicles and arbuscules, but not the growth of hyphae in the guayule roots inoculated with Glomus intraradices (Pfeiffer and Bloss 1998). Under higher $\mathrm{NaCl}$ concentrations, endosymbionts may be reduced to coenocytic hyphae only as under waterlogged conditions and act almost as benign parasite.

There are few studies indicating that mycorrhizal fungi can increase growth of plants growing in saline habitats (Ojala et al. 1983; Pond et al. 1984). VA-mycorrhizal fungi may have the ability to protect plants from salt stress (Hirrell and Gerdemann 1980; Rosendahl and Rosendahl 1991), but the mechanism is not fully understood. The few data available at present suggest that fungi do have a potential to enhance plant growth but further studies are needed with additional plants, fungi under variable saline conditions.

VA-mycorrhizal fungi most commonly observed in saline soils are Glomus spp. (Juniper and Abbott 1993) which suggest that this may be adapted to grow in saline conditions, but ecological specificity has not been demonstrated. There is evidence that VAM species distribution is markedly changed with increased salinity (Stahl and Williams 1986).

Soil salinity and waterlogging often co-occur and interact in low-lying areas but no attempts have been made to study their collective effects on VAM. VA-mycorrhizal infection and VA- mycorrhizal fungal propagules have been observed in inundated salt marshes (Khan and Belik 1994). A comparative study of the effects of salinity and the co-related stress of low water potential on host plant and VAM fungus is desirable before plant endophyte combinations are selected for. Also, it is necessary to separate $\mathrm{Na}$ effects from other salt effects. 
Aforementioned studies show that flood tolerant plants and VA endobiont fungi exist together. Whether these fungi are adapted to such conditions play any role in alleviating plant stress brought on by flooding under aquatic environments had yet to be elucidated. Some recent studies in rice-growing areas such as India, Thailand and USA and our preliminary investigations in Australia suggest that VA mycorrhizal endobiont would benefit both wetland and upland rice. But there are many biological principles which need to be explained, ie. how the infection occurs under flooded conditions and what initiates it, how the nutrients are obtained by the VAM fungi under waterlogged conditions, what VAM fungi are adapted to aquatic conditions, what conditions favour the symbiosis, etc. Close attention should be given to the effects of edaphic, abiotic (physical and chemical) and biotic (soil microflora and fauna, including pathogens) factors on the mycorrhizal symbiosis while researching this area.

\section{REFERENCES}

ANDERSON, R.C., A.C. LIBERTA and L.A. DICKMAN. 1984. Interaction of vascular plants and vesiculararbuscular mycorrhizal fungi across a soil moisture gradient. Oecologia, 64: 111-117.

BETHLENFAlVAY, G.J. 1992. Mycorrhizae and crop production. In Bethlenfalvay, G.J. and Lindermann, R.G. (Eds). Mycorrhizae in substantial agriculture. ASA spec. Pub. 54, Am. Soc. Agron. Madison, Wisconsin, p. 1-27.

BETHLENFALVAY, G.J., R.S. THOMAS, S. DAKESSIAN, M.S. BROWN, and R.N. AMES. 1988. Mycorrhizae in stressed environments: Effects on plant growth, endophyte development, soil stability and soil water. In Whitehead, E.E. Arid lands, Today and Tomorrow. Westview Press, Boulder, Co. p. 1015-1029.

JUNIPER, S. and L. ABBOTT. 1993. Vesicular and arbuscular mycorrhizae and soil salinity. Mycorrhizae, 4: 45-57.

KHAN, A.G. 1974. The occurrence of mycorrhizae in halophytes, hydrophytes and xerophytes, and of endogone spores in adjacent soils. J. Gen. Microbiol., 81: 7-14.

KHAN, A.G. 1978. Vesicular-arbuscular mycorrhizas in plants colonising black wastes from bituminous coal mining in the Illawarra Region of New South Wales. New Phytol., 81: 53-63.

KHAN, A.G. 1981. Growth responses of endomycorrhizal onions in unsterillised coal waste. New Phytol., 87: 363-367.

KHAN, A.G. 1988. Inoculum density of Glomus mosseae and growth of onion plants in unsterilized bituminous coal spoil. Soil Biol. Biochem., 20 (5): 749-753.

KHAN, A.G. 1993a. The occurrence and importance of mycorrhizae in aquatic trees of New South Wales, Australia. Mycorrhizae. 3: 31-38.

KHAN, A.G. 1993b. The influence of redox potential of formation of mycorrhizae in trees from wetland and water-logged areas of New South Wales, Australia. Abst. 9th North Am. Conf. on Mycorrhizae, Aug. 8- 12, 1993, University of Guelph, Guelph, Ontario, p. 18. 
KHAN, A.G. 1993c. Vesicular-arbuscular mycorrhizae (VAM) in aquatic trees of New South Wales, Australia, and their importance at land-water interface. In Gopal, B., Hillbricht-Ilkowska, A. and Wetzel, R.G. (eds). Wetland and ecotones: studies on land-water interaction, National Institute of Ecology, New Delhi, p 173-180.

KHAN, A.G. and M. BELIK. 1994. Occurrence and ecological significance of mycorrhizal symbiosis in aquatic plants. In: Varma A, Hock B (Eds). Mycorrhiza: Function, Molecular Biology and Biotechnology. Springer-Verlag, Heidelberg, Germany, 1994 (in Press).

KLUDGE, H.K., R.D. DELAUNE and W.H. PATRICK JR. 1993. Aerenchyma formation and methane and oxygen exchange in rice. Soil Sci.Soc. Am. J., 57: 386-391.

LIBERTA, A.E., R.C. ANDERSON and L.A. DICKMAN. 1983. Vesicular-arbuscular mycorrhizae fragments as a means of endophyte indentification at hydrophytic sites. Mycologia, 75: 169-171.

OJALA, J.C., W.M. JARRELL, J.A. MENOE and E.L.V. JOHNSON. 1983. Influence of mycorrhizal fungi on the mineral nutrition and yield of onion in saline soil. Agron. J., 75: 255-259.

PFEIFFER, C.M. and H.E. BLOSS. 1988. Growth and nutrition of guayale (Parthenium argentatum) in a saline soil as influenced by vesicular-arbuscular mycorrhizae and phosphorous fertilisation. New Phytol., 108: 315-321.

POND, E.C., J.A. MENOE and W.M. JARELL. 1984. Improved growth of tomatoes in salinized soil by vesicular-arbuscular mycorrhizal fungi collectors from saline soils. Mycologia, 76: 74-84.

ROSENDAHL, C.N. and S. ROSENDAHL. 1991. Influence of vesicular-arbuscular mycorrhizal fungi (Glomus spp.) on the response of cucumber (Cucumis sativus L.) to salt stress. Environ. Exp. Bot, 31: 313-318.

STAHL, P.O. and S.E. WILLIAMS. 1986. Oil shale process water affects activity of vesicular-arbuscular fungi and Rhizobium four years after application to soil. Soil Biol. Biochem. 18: 451-455.

SYLVIA, D.M., L.C. HAMMOND, J.M. BENNETT, J.H. HAAS and S.B. LINDA. 1993. Field response of maize to a VAM fungus and water management. Agron. J. 85. 